\title{
CAPACIT @NDO: uma proposta de formação docente utilizando o Moodle
}

\author{
Cátia Alves Martins \\ Mestranda do Programa de Pós-Graduação em Ciências e Matemática PUCRS \\ catia.amartins@ibest.com.br \\ Lúcia M. Martins Giraffa \\ Professora pesquisadora do Mestrado em Educação em Ciências e Matemática PUCRS \\ giraffa@pucrs.br
}

Resumo: Este artigo apresenta reflexões a cerca da utilização do MOODLE como espaço de integração e suporte para capacitação docente considerando a abordagem baseada na metodologia de educar pela pesquisa. A expansão da Internet e seus recursos e a constatação da necessidade de capacitar os professores para conviver com os alunos "nativos digitais", nos remetem a necessidade de organizar a formação docente considerando a inclusão das Tecnologias Digitais como recurso para construção de conhecimento. Observa-se que a maioria dos professores teve uma formação tradicional e aprenderam a construir conhecimento de forma diferente dos seus alunos, os "nativos digitais". Buscou-se com este trabalho ofertar uma proposta de formação de professores do Ensino Fundamental que aproxime da sala de aula com o cotidiano de uma geração acostumada a usar o ciberespaço como veiculo de comunicação e expressão.

Palavras-chave: Formação docente, educar pela pesquisa, cibercultura, Moodle.

CAPACIT@ @ndo: a proposal for teacher training using Moodle

Abstract: This paper presents our proposal to aid Elementary Schools teacher's to develop skills in order to organize their face-to-face class activities using MOODLE Education through Research (ETR) viewpoint. This paper also intends to point out some important issues regarding teacher's background including the necessity to improve and to upgrade the set of requirements needed to be considered a member of the Internet cyberspace, and use its resources and services in order to organize student's activities. Since nowadays most of the teachers do not have skills or formation to cope the challenges offered by these new technologies.

Keywords: cyber culture, teacher's background, Moodle, Education through Research.

\section{Introdução}

O docente que utiliza recursos associados às Tecnologias Digitais (TDs) em suas aulas certamente conseguiu transpor o nível de analfabetismo tecnológico (Assmannn, 1998). Contudo a maioria dos docentes que atuam nas escolas é considerada imigrantes digitais (Prensky, 2001) e necessitam adquirir competências e habilidades que os qualifiquem a trabalhar de forma síncrona com o contexto de percepção e construção de conhecimento que seus alunos, nativos digitais, percorrem. Entretanto será que a apropriação de competências e habilidades tecnológicas por parte dos docentes torna-se requisito suficiente para transformar as práticas escolares e contextualizá-las frente às necessidades propostas pela cibercultura? 
Acredita-se que não é apenas a apropriação e uso das TDs que faz diferença no processo de ensino e aprendizagem (Valente, 2008). Para tanto conhecer o funcionamento do computador, saber navegar na internet, utilizar recursos de buscadores, usar o gerenciador de softwares, editores de texto, planilhas ou apresentações, apresenta-se como habilidades tecnológicas que proporcionam a digitalização das práticas escolares. Todavia as potencialidades de interação, colaboração, exploração, simulação, investigação presentes nas TDs (Ponte \& Canavarro, 1997) sugerem transformações nas formas de ensinar e aprender, uma vez que utilizando estes recursos construímos e consumimos conhecimento de forma diferente da ênfase na instrução, presente na formação da maioria dos docentes imigrantes digitais.

O que faz a diferença no uso pedagógico das TDs é o tipo de planejamento e organização do projeto pedagógico o qual deve focar a aprendizagem como elemento central do processo. Ou seja, utilizar a tecnologia a serviço da Educação e não a Educação subjugada e restrita às ofertas tecnológicas. $\mathrm{O}$ viés para investimentos em mais pesquisa, reflexão e criticidade na escola perpassa pela formação docente. Demo (2002) analisa a prática docente como atividade profissional desgastante e propensa ao "envelhecimento rápido da competência", a qual só se renova e, por conseqüência, transforma o espaço escolar, no desenvolvimento de novas competências profissionais. A capacitação com enfoque em TDs deve privilegiar a investigação reconstrutiva (Demo, 2002), abrangendo além dos aspectos informativos espaço para trocas de experiências, relatos, produção de materiais, construção de projetos. Esse enfoque de relação e reflexão com a prática deve acontecer de forma simultânea com os aspectos informativos. As informações adquirem valor e potencial quando podem ser transformadas em habilidades e competências. O docente a partir das informações transforma sua relação com o conhecimento e melhora a sua prática.

Este artigo apresenta algumas reflexões sobre a formação docente frente à construção de competências tecnológicas e pedagógicas. Utilizando o Ambiente Virtual de suporte ao Ensino-Aprendizagem (AVEA) Moodle ${ }^{1}$ apresenta-se uma proposta de formação ao docente que atua nas séries finais do Ensino Fundamental com enfoque na metodologia de educar pela pesquisa. $\mathrm{O}$ artigo está organizado da seguinte forma: a seção dois apresenta uma reflexão sobre o atual cenário nacional de capacitação docente para o uso das TDs; a seção três trata das características consideradas necessárias a formação do docente no contexto do ciberespaço criado pela Internet; a seção quatro apresenta uma proposta de capacitação docente frente aos desafios da cibercultura; e na seção cinco são apresentadas as considerações finais acerca deste trabalho.

\section{Cenários de formação docente e pistas rumo às capacitações}

Realizou-se um levantamento dos programas de formação docente em nível nacional no período de 2007-2008 (em órgãos governamentais, instituições de ensino e empresas mercadológicas) com enfoque a utilização de TDs e os pressupostos metodológicos utilizados durante a capacitação. A principal fonte de pesquisa foi à internet dada à natureza dos dados. A análise do cenário brasileiro possibilitou identificar cinco grupos de público-alvo: docentes do Ensino Superior, docentes em geral (sem delimitação do nível de ensino em que atua), docentes da Educação Básica,

1 MOODLE - Modular Object Oriented Dynamic Learning Environment. Disponível em: www.moodle.org 
docentes do Ensino Profissionalizante, e interessados em geral (sem delimitação específica). De acordo com os índices apresentados na Figura 1, 45\% dos cursos de formação destinam-se a professores do Ensino Superior; 7\% a professores da Educação Básica; $19 \%$ a professores em geral; $7 \%$ a professores do Ensino Profissionalizante; e $22 \%$ destinam-se a interessados em geral.

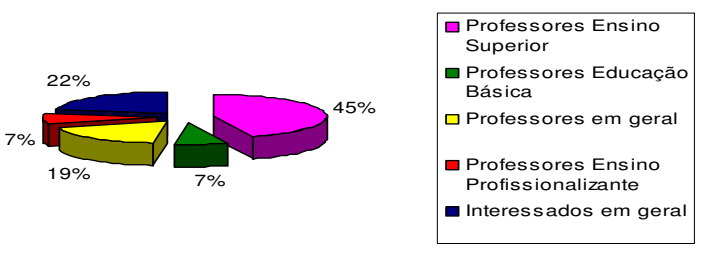

Figura 1 - Distribuição percentual dos cursos de capacitação docente em AVAs por público-alvo.

Os índices apresentados acima evidenciam que a maioria dos cursos de capacitação é direcionada a docentes que atuam no Ensino Superior. Nas pesquisas realizadas não se encontrou nenhum curso específico a docentes do Ensino Fundamental. Com essa formatação sugere-se que a formação do docente independe do nível de ensino em que atua e não se diferencia pela clientela que o docente atende. Entretanto entende-se que a faixa etária dos alunos atendidos norteia a formatação da capacitação específica, visto que os objetivos traçados em uma situação e outra são diferentes.

Entre os pressupostos teóricos e práticos evidenciados observou-se que são informados os seguintes aspectos: histórico da informática educativa, preparação de material digital, papéis do aluno e professor, direitos autorais, avaliação via AVA, uso de tutoriais, metodologia de projetos.

Verifica-se que a configuração das capacitações prevê que $30,77 \%$ dos cursos privilegiam a preparação de material digital, seguido percentualmente pelo uso de tutoriais, 19,23\%, como ferramenta pedagógica. A prevalência desses conteúdos pode ser indicador do atual paradigma pedagógico vigente: a instrução. Os cursos continuam a privilegiar (tal como muitos cursos sem uso do ferramental tecnológico) formas de ensinar e aprender baseados no seguimento de instruções. De tal forma que os docentes adquirem conceitos e habilidades para utilizar os recursos tecnológicos e didáticos sem propriamente desenvolverem a reflexão sobre qual paradigma educacional se fortalecem esses recursos, sendo estes adaptados a qualquer ênfase pedagógica ou a que lhes é mais cômoda.

Partindo dessas análises averigua-se a lacuna de investimentos em cursos de formação destinada aos docentes do Ensino Fundamental e acredita-se (Santos, 1995) que o desempenho dos docentes depende dos modelos de ensino internalizados ao longo de sua trajetória como estudante e em contato com outros professores. Ora, a maior parte da trajetória dos imigrantes digitais condiz com um modelo de transmissão que dificilmente será transposto se não participarem de momentos que privilegiem outras metodologias de ensino e aprendizagem, refletindo sobre suas próprias práticas.

\section{Formação do docente imigrante digital}


Em um primeiro momento a recuperação da competência docente pode significar o desenvolvimento de habilidades instrumentais para o uso das TDs visto que estas emergiram após seu período de formação inicial. Faz-se necessário instigar o domínio de habilidades para o uso do computador, uso de softwares específicos, de acesso, navegação e comunicação na rede. Todavia o domínio dessas funcionalidades tecnológicas tende a promover a superação das dificuldades de apropriação instrumental, que podem servir tanto para o meio pessoal quanto profissional. Considerado por muitos como trivial é o emprego das competências tecnológicas para subsidiar o trabalho docente. Assim investe-se cada vez mais na implementação de novas tecnologias (NT) nos espaços escolares (investimento necessário visto a precariedade de recursos de muitas instituições públicas no país). Diante da possibilidade de utilizar as NT, muitos docentes expandem para os espaços informatizados práticas transmissoras de conhecimento, reproduzindo digitalmente as metodologias instrucionais da mesma forma que já se faz utilizando a oralidade ou o lápis e o papel. O que se busca é utilizar o suporte digital como forma de auxiliar na transformação de práticas transmissoras de conhecimento em práticas exploratórias e investigativas (Ponte, 2000). Levar para a sala de aula não as TDs como meio digital de instrução ou como disciplina e correr o risco de continuar mecanizando o ensino e a aprendizagem ou fragmentar ainda mais o conhecimento. Utilizar as TDs para percorrer caminhos de aprendizagens mais envolventes e tipicamente reconstrutivos (Demo, 2008) requer a reconstrução de competências pedagógicas, tema norteador do experimento piloto realizado.

\section{Delimitando uma proposta para capacitação docente}

Diante das questões inicialmente levantadas, realizou-se um experimento piloto com um docente voluntário das séries finais do Ensino Fundamental em uma instituição pública. O docente selecionado era regente da disciplina de Matemática. A proposta da capacitação consistiu em fomentar a reconstrução de conhecimento docente de forma exploratória, investigativa e cooperativa, objetivando superar a visão mecanicista de aprender e ensinar, buscando reflexões sobre a prática de sala de aula e desenvolvendo competências tecnológicas e pedagógicas para o uso das TDs.

Optou-se por estruturar o trabalho de formação utilizando uma TD que possibilitasse a construção de uma comunidade de ensino e aprendizagem centrada em uma sala de aula virtual: a plataforma o Moodle. A escolha recaiu no Moodle por ser uma plataforma construída a partir de uma perspectiva construtivista que privilegia a investigação e a colaboração através de sua estrutura e recursos disponíveis. Possui funcionalidades formativas (chats, fóruns, Wikis, blogs, glossários, questionários editáveis, Hot Potatoes ${ }^{2}$ ) e informativas (recursos de textos, áudio, vídeo e links de pesquisa). Além disso é aceito mundialmente (inclusive o MEC a adotou como plataforma oficial das escolas públicas no país), o que influência a comunidade de desenvolvedores a qual segue investindo na sua constante atualização. O MOODLE é uma plataforma Open Source (aberta, livre, gratuita), permitindo que o docente a reutilize em suas práticas docentes. A formação teve como fio condutor a proposta pedagógica de metodologia educar pela pesquisa via uso das TDs e consistiu em uma sucessão de atividades organizadas em três fases (Figura 1). Sucintamente as fases podem ser assim caracterizadas: a fase um propunha a instrumentalização digital e pedagógica com o auxílio dos recursos da internet, entre eles o ambiente Moodle; a fase dois 
objetivava propor atividades organizadas na fase um para uma turma das séries finais do Ensino Fundamental via Moodle; a fase três realizou a avaliação da capacitação pelo docente e a avaliação da proposta pelos alunos.

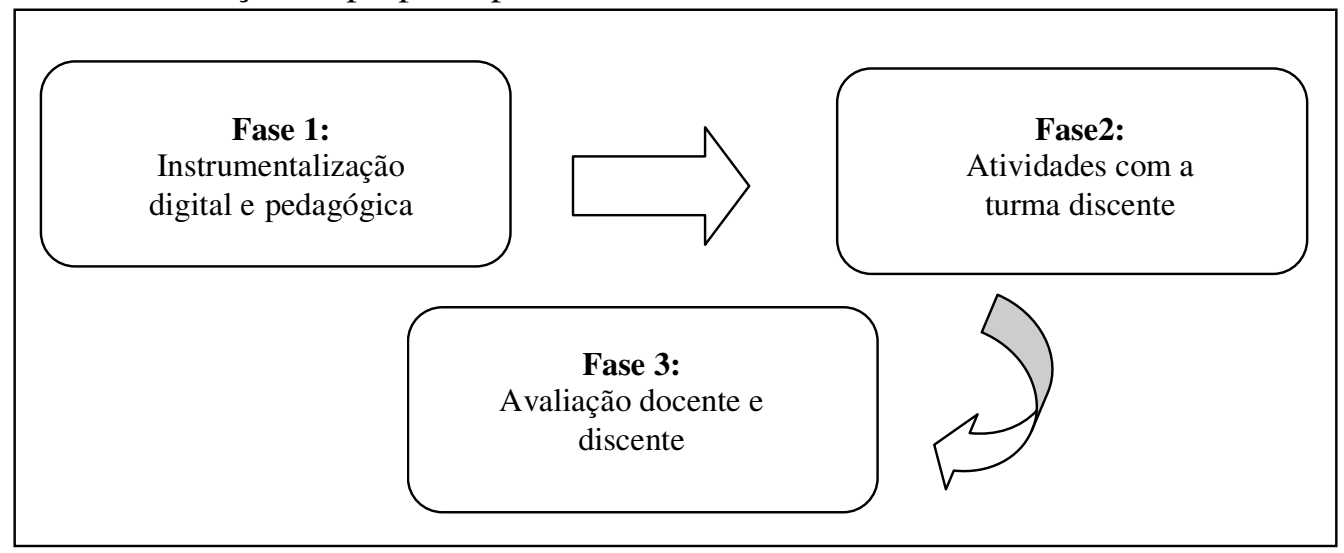

Figura 2 - Experiência Prática de capacitação docente

A capacitação privilegiou atividades assíncronas via Moodle, três encontros presenciais e um momento de transposição didática. As atividades assíncronas distribuídas em tópicos permitiam que o docente organizasse o seu tempo da forma que melhor lhe convinha, sendo monitorado e estimulado a apresentar reflexões semanais sobre os temas propostos.

Para cada atividade programada foram sugeridas leituras de documentos criados digitalmente ou disponíveis na internet sobre assuntos relacionados à cibercultura, a utilização das TDs na educação, a fundamentação teórica da metodologia educar pela pesquisa, contextualização de conteúdos curriculares e foram delineadas tarefas a serem desenvolvidas. As atividades da primeira fase subdividiram-se em instrumentalização digital e suporte pedagógico. Nesta fase propôs-se estudo e reflexão sobre os impactos da cibercultura na educação, os desafios docentes, a metodologia educar pela pesquisa, construção de atividades envolvendo conteúdos curriculares. A dinâmica das atividades utilizou o enfoque da metodologia educar pela pesquisa, propondo tarefas reflexivas, investigativas e colaborativas. Privilegiou-se o aprender fazendo docente, pois segundo Demo (2002) o professor que não vivencia situações de pesquisa não desenvolve competências de investigação e torna-se competente apenas em dar aula e copiar do livro texto a aula pronta. Na segunda fase o docente conduziu as atividades construídas na fase um, abordando um conteúdo específico de Matemática em uma turma de sua regência no Ensino Fundamental com o auxílio da pesquisadora.

$\mathrm{Na}$ terceira fase avaliou-se o experimento do ponto de vista dos alunos envolvidos e do docente utilizando-se a funcionalidade de questionário editável do MOODLE, composto por questões objetivas e descritivas.

A avaliação discente continha questões que procuravam avaliar a percepção do aluno sobre a construção do conceito proposto, a motivação para o estudo via funcionalidades do ambiente e a metodologia de trabalho adotada. A maioria dos alunos $(46,67 \%)$ apontou que o principal auxílio das TDs durante o experimento foi à compreensão do conteúdo, ou seja, a construção do conceito.

De acordo com 53,33\% dos alunos os recursos das TDs e da internet são recursos que motivam ao estudo da disciplina, bem como $80 \%$ dos alunos se mostraram favoráveis a utilizar novamente o ambiente virtual. Essa constatação reforça o que 
Cunha (2005) aponta como um dos desafios docentes deste século: como motivar os alunos e como ensinar considerando as informações disponíveis na internet.

A avaliação docente divide-se em duas categorias: as práticas pedagógicas nos momentos de capacitação e as percepções durante a transposição didática. As questões objetivas continham cinco alternativas de resposta, as quais foram associadas a notas em uma escala de 1 a 5 , sendo 5 a nota de maior satisfação, conforme Tabela 1 .

Tabela 1 - Comparação das notas do instrumento de avaliação

\begin{tabular}{ll}
\hline Nota & Significado \\
\hline $\mathbf{5}$ & Muito importante \\
$\mathbf{4}$ & Importante \\
$\mathbf{3}$ & Média importância \\
$\mathbf{2}$ & Pouco importante \\
$\mathbf{1}$ & Não importante \\
\hline
\end{tabular}

O questionário foi respondido pelo docente e a nota atribuída a cada questão é apresentada na Figura 3.

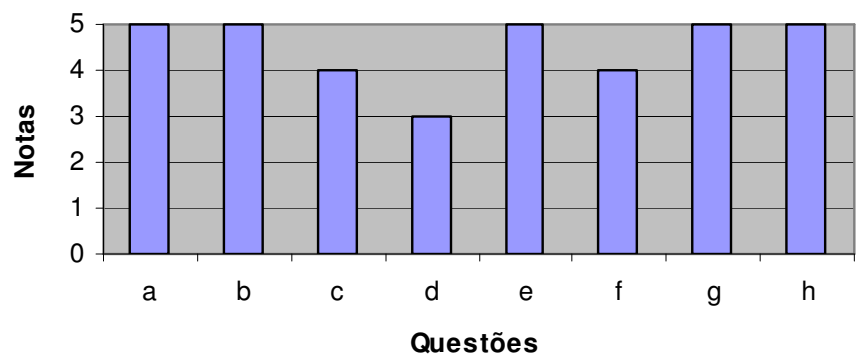

Figura 3 - Notas atribuídas por questão

Quanto às práticas pedagógicas o docente apontou dificuldades em interagir virtualmente no ambiente no início do experimento.

De acordo com o gráfico é possível constatar que as notas mais baixas estão relacionadas à questão "d" (A experiência de interagir virtualmente é uma possibilidade de construir conhecimento de forma ...) o que permite indicar a dificuldade docente em perceber outras formas de construir conhecimento, além das técnicas orais e de lápis papel. Isso se verificou no decorrer da capacitação quando o docente apresentava dificuldades para postar suas reflexões na elaboração do glossário ou contribuir nos primeiros fóruns, sendo necessário contato telefônico para superar a situação. Mais adiante sugeriu encontro presencial para a exploração de alguns softwares agregados ao ambiente, uma vez que encontrou dificuldades em seguir as instruções virtuais. Agregar habilidades de interagir virtualmente é um ponto latente nas formações docentes.

A questão "c" (As atividades de escrever o que se compreende sobre determinados conceitos específicos é uma prática pedagógica...) alcançou nota 4. Nas práticas de Matemática não é comum escrever a compreensão do conteúdo. Entretanto a experiência virtual requereu do docente habilidade de escrita coerente com as suas reflexões. Comunicar o que se pensa sobre um determinado assunto é uma forma de elaborar o pensamento e clarear as percepções a respeito do mesmo. A interação virtual pré-dispõe os sujeitos a construírem habilidades de comunicação escrita claras e objetivas no sentido de evitar ambigüidades ou incompreensões. 
A questão "f" (Os recursos do computador e da Internet representam ferramentas de trabalho pedagógico possíveis na tua área de atuação de forma...) pontuou nota 4 . $\mathrm{O}$ docente relatou que utilizar os recursos da internet em aula requer maior planejamento para não recair em simples cópia: "utilizando à internet as aulas ficam mais ricas, os alunos tem acesso a diferentes fontes de informação e têm mais chance de entender o conteúdo (...) o professor é que precisa tempo para organizar o roteiro da aula, caso contrário as facilidades de cópia podem induzir o aluno ao menor esforço". Utilizar os recursos da internet na mesma dinâmica da aula copiada não acrescenta competências ao aluno, apenas passa-se do quadro-de-giz para a digitalização das aulas. O docente associou à internet a necessidade de mudança na prática pedagógica, ou seja, o planejamento unilateral (instrução professor/aluno) não dá conta das possibilidades de uso dos meios tecnológicos, sob a ameaça de estimular o não pensar.

O docente atribuiu nota máxima a relação entre envolvimento dos alunos na realização das tarefas propostas e metodologia adotada, destacando que os alunos "têm interesse por atividades de descoberta e por questões curiosas que envolvem o conteúdo". Perceber o potencial da metodologia para o aprendizado do aluno é uma indicação da necessidade de rever as práticas de sala de aula.

A média geral das questões objetivas ficou em 4,5, o que demonstrou satisfação com a capacitação desenvolvida e com a metodologia proposta.

Ao longo do experimento foram categorizadas as competências consideradas necessárias de serem desenvolvidas e agrupadas em cinco grandes grupos: alfabetização tecnológica, competência específica, competência tecnológica específica, competência cooperativa e competência pedagógica:

- Alfabetização tecnológica - utilização de recursos do gerenciador de programas, de editor textos, envio e recebimento de mensagens, postagem de produções no ambiente, uso de ferramentas de busca, download e upload de arquivos;

- Competência específica - revisão de alguns conceitos específicos, intrínsecos a prática docente de Matemática no Ensino Fundamental;

- Competência tecnológica específica - manuseio e análise de softwares específicos (neste caso softwares de ensino de Matemática) ao desenvolvimento de conteúdos, priorizando os softwares livres;

- Competência cooperativa - envolvimento em atividades colaborativas, interação com o material de estudo e com os pares, promoção de troca de experiências, reelaborações pessoais e grupais;

- Competência pedagógica - metodologia do educar pela pesquisa promovendo reflexões, explorações, investigações sobre conteúdos específicos e sobre as práticas, desenvolvimento de atividades de interpretação e reelaboração de textos científicos, elaboração de material didático próprio, construção de projeto de trabalho.

No desenvolver do experimento a pesquisadora colocou-se como mediadora do processo de aprendizagem. Estimulou a participação no ambiente, propondo a leitura e construção de materiais, a interação através de funcionalidades assíncronas como os fóruns, os glossários e as wikis, sugerindo recursos, alcançando materiais, discutindo as publicações no ambiente e monitorando a participação.

\section{Considerações Finais}


O experimento realizado permitiu que o docente refletisse, elaborasse e efetivasse uma proposta apoiada na metodologia de educar pela pesquisa com sua turma, desenvolvendo um conteúdo da série, via o ambiente Moodle. Este funcionou como um recurso virtual complementar às atividades presenciais. As funcionalidades do Moodle permitiram que os alunos tivessem contato uns com os outros e ampliassem o espaço físico do ambiente escolar. Os recursos tecnológicos disponíveis pela estrutura do Laboratório de Informática, com a comunicação virtual (que já utilizada em momentos extraclasse), com os colegas (que dificilmente se formaria com os alunos enfileirados) através das interações via fórum, construção de glossário, elaboração de texto colaborativo sobre o tema.

Acredita-se que mais do que privilegiar o acesso à informação e a comunicação à Internet e seus recursos, as salas de aula virtuais criadas nos AVEAs são espaços profícuos e contextualizados que auxiliam na aprendizagem dos nativos digitais. Os recursos multimídias, facilmente incorporáveis no AVEA, auxiliam na reconstrução significativa de conhecimento desde que o docente tenha construído uma proposta que enfatize a reflexão crítica. O docente do século XXI deve possuir, além do domínio de conteúdo específico, competências para desenvolver que estimulem a aprendizagem em tempos de cibercultura (Martins e Giraffa, 2008). Entretanto esta atitude prescinde de conscientização do docente acerca da necessidade de atualizar-se continua e periodicamente. Segundo Demo (2000) não se pode enquanto educador crítico sofrer contradição performativa insistindo que o aluno estude todos os dias sem que os professores mesmos jamais estudem.

A capacitação/formação via Moodle ainda pode permitir o estreitamento de relações afetivas entre o grupo de trabalho da escola ou da rede de ensino, conferindo caráter de comunidade virtual de aprendizagem que troca experiências e aprendizados, gerando outras reflexões individuais e/ou grupais.

Sem o apoio da direção e dos pais dos alunos envolvidos não seria possível obter-se sucesso na experimentação. Múltiplos fatores concorrem para que um projeto de capacitação docente logre êxito. Não é uma tarefa trivial e exige um forte planejamento, equipe qualificada e predisposição do docente em refletir acerca do seu papel e competências face aos desafios ofertados pela cibercultura. Sentir-se um imigrante não é problema desde que se façam movimentos em direção a tornar-se um nativo digital. Vive-se a aparente contradição de "nascer imigrante" e tornar-se nativo. Mais um desafio imposto pela imersão da sociedade numa cultura de uso e consumo de tecnologia.

\section{Referências Bibliográficas}

ASSMANN, Hugo. Metáforas novas para reencantar a educação: epistemologia e didática. Piracicaba: UNIMEP, 1998.

CUNHA, Maria Isabel da. Bom professor e sua prática. São Paulo: Papirus, 2005.

DEMO, Pedro. Saber pensar. São Paulo:Cortez, 2000.

Educar pela pesquisa. Campinas: Autores Associados, 2002. 
TICs e Educação Disponível em:

http://pedrodemo.sites.uol.com.br/textos/tics.html Acesso em: agosto 2008.

MARTINS, Cátia Alves; GIRAFFA, Lúcia M. M. Metodologia de Projetos via

MOODLE: uma investigação acerca das competências necessárias aos docentes do Ensino Fundamental. In: XIV Workshop de Informática na Escola, 2008, Belém. Procedings of XXVIII Congresso da Sociedade Brasileira de Computação, 2008.

PONTE, João Pedro da. Tecnologias de informação e comunicação na formação de professores: que desafios. In: Revista Iberoamericana de Educación. Madrid:

Organización de Estados Iberoamericanos para la Educación, la Ciencia y la cultura, 2000. p.63-90

PONTE, João Pedro da; Canavarro, Ana paula. Matemática e Novas tecnologias. Lisboa:Universidade Aberta,1997.

PRENSKY, Marc. (2001). Digital Natives , Digital immigrants. Disponível em: http://www.marcprensky.com/writing/ Acesso em agosto 2008.

SANTOS, Lucíola Licínio. Formação do professor e pedagogia crítica. In: FAZENDA, Ivani. A Pesquisa em Educação e as transformações do conhecimento. Campinas: Papirus, 1995. p.17-41

VALENTE, José Armando. Formação de professores para uso de informática na educação. Disponível em:

http://www.tvebrasil.com.br/salto/boletins2001/tec/tectxt4.htm. Acesso em abril: 2008 